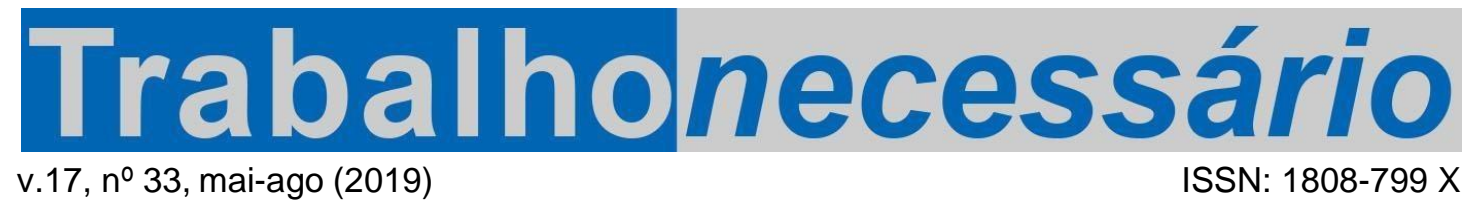

\title{
PROCESSOS FORMATIVOS DO MST: DESAFIOS E LIMITES HISTÓRICOS 1
}

\author{
Ademar Bogo ${ }^{2}$ \\ Resumo \\ Maria Nalva Rodrigues de Araújo Bogo ${ }^{3}$
}

Este artigo tem como objetivo avaliar os elementos constitutivos do MST como movimento social no bojo das contradições capitalistas, focando especialmente as estratégias de luta pela terra e, consequentemente, a luta pela educação e sua relação com as alternativas de organização do trabalho, experimentadas pelo Movimento. Focaliza os desafios frente a proposição do Movimento quando este assume em sua plataforma a agroecologia como modelo produtivo alternativo em contraposição à agricultura capitalista/agronegócio. Questiona em que medida este modelo contribui para construção do projeto histórico socialista. Ao final, apresenta alguns desafios ao Movimento para o avanço de um projeto histórico emancipador.

Palavras-chave: MST; luta social; trabalho; Educação; Agroecologia

\section{PROCESOS FORMATIVOS DEL MST: DESAFÍOS Y LIMITES HISTORICOS}

\section{Resumen}

Este trabajo tiene como objetivo evaluar los elementos constitutivos del MST como movimiento social en el centro de las contradicciones capitalistas, focando en especial las estrategias de lucha por la tierra y, consecuentemente, la lucha por la educación y su relación con las alternativas de organización del trabajo, experimentadas por el movimiento. Se enfoca los desafíos del Movimiento cuando éste asume en su plataforma la agroecología como modelo productivo alternativo en contraposición a la agricultura capitalista / agronegocio. Cuestiona en qué medida este modelo contribuye a la construcción del proyecto histórico socialista. Al final, presenta algunos desafíos al movimiento para el avance de un proyecto histórico emancipador.

Palabras clave: Ciencia y Tecnología; lucha social; trabajo; la educación; Agroecología

\section{MST AND ITS FORMATION PROCESSES: CHALLENGES AND HISTORICAL LIMITS}

\begin{abstract}
This article aims to evaluate the constituent elements of MST as a social movement in the midst of capitalist contradictions, focusing specially on the strategies on fighting for land and consequently on the fight for education and its relations with the alternatives of work organization experienced by the movement. It Also focus on the challenges It faces when it proposes agroecology as an alternative production model on its plataform instead of capitalist agriculture/Agribusiness. It asks whether to what extent this model contributes to the socialist historic project. At the end it presents some challenges of the movement for the advancement of a historic emancipatory project.
\end{abstract}

Keywords: MST; social struggles; Education; Agroecology.

${ }_{1}^{1}$ Artigo recebido em 01/03/19. Primeira Avaliação em 07/04/19. Segunda avaliação em 22/05/19. Aprovado em 13/06/19. Publicado em 04/07/2019. DOI: https://doi.org/10.22409/tn.17i33.p29368. 2Doutorado em Filosofia; Prof. da Faculdade Sul Bahia-FASB; e-mail: abogo@oi.com.br; https://orcid.org/0000-0002-6864-7113.

${ }^{3}$ Doutorado em Educação; prof ${ }^{a}$ titular da Universidade do Estado da Bahia-UNEB; e-mail: mnaraujo@uneb.br; https://orcid.org/0000-0002-9020-2217 


\section{Introdução}

Buscamos, neste artigo, tecer algumas reflexões sobre a constituição e o desenvolvimento político e histórico do MST como movimento social, no bojo das contradições capitalistas e das suas próprias contradições, a partir da década de 1980, tendo como referência a questão da luta pela terra e pela reforma agrária, a formulação de uma proposta de produção e a construção de um programa de educação emancipatória.

Partimos do pressuposto de que a análise histórica do Movimento, somente pode ser entendida em meio às contradições econômicas, políticas e sociais, bem como os processos de desenvolvimento científico e tecnológico que permeiam a modernização constante das forças produtivas e influem diretamente sobre as relações sociais e de produção. Diante disso, nos propomos analisar as proposições do MST no percurso de seu surgimento, implantação e afirmação social, principalmente quando assume em sua plataforma a agroecologia como forma de produção e organização produtiva em contraposição à agricultura capitalista promovida pelo agronegócio.

Trata-se de um artigo que tem como base a pesquisa bibliográfica e documental, cuja coleta dos dados foi realizada em documentos e publicações do próprio Movimento. Quanto à estrutura do trabalho, está organizado em quatro partes: numa primeira, apresentamos reflexões sócio-históricas acerca do Movimento dos Trabalhadores Rurais Sem Terra-MST. Na segunda parte abordamos as tentativas do MST para organizar o trabalho e a produção, bem como discutir os dilemas enfrentados por ele na conjuntura socioeconômica e política brasileira no período de sua existência. Na terceira parte, por meio da pesquisa documental, buscamos mostrar as sistematizações do MST em busca de uma pedagogia do trabalho por meio das escolas dos assentamentos. Nas considerações finais elencamos alguns desafios que se colocam para o movimento no que toca à agroecologia como modelo de produção e trabalho para a construção do projeto político histórico.

\section{O processo de desenvolvimento sócio-histórico do MST}

No início da década de 1980, ainda sob forte vigilância da ditadura militar, o 
processo de organização política, sindical e popular era imenso, fazendo com que as lutas pelos direitos e, dentre eles, o acesso à terra e ao trabalho demandasse novas formas de organização. O Movimento dos Trabalhadores Rurais Sem Terra, organizado ainda por dentro do movimento sindical rural, destacou-se pela sua capacidade de enfrentamento e conquistas frente aos latifúndios.

A presença desse novo "sujeito coletivo" na História da luta pela terra, no cenário nacional, chamou a atenção pelas suas características e métodos de organização, forjados sobre a tradição da terra como mercadoria, a luta de resistência dos posseiros, a repressão policial e o conservadorismo das diretorias dos sindicatos rurais. Por isso, o processo de organização do MST, apesar de espelhar-se em diversas experiências locais e internacionais, teve que ser a referência de si mesmo, pois, ao mesmo tempo em que formava a sua força ativa, formava-se como estrutura inovadora de organização.

Esse fazer e fazer-se com características diferenciadas, próprias ou ressignificadas dos processos anteriores, seguiu oportunamente realizando três combinações nas práticas inovadoras na luta de classes, a saber: a) a cobrança das dívidas sociais, b) a ocupação de lugar e c) a mística transformativa.

Em relação à cobrança das dívidas sociais, consideramos que a concentração da terra no longo período da colonização brasileira fizera com que não apenas o direito ao trabalho fosse vilipendiado, mas, junto a ele, o direito à escolarização, a formação profissional, o desejo dos jovens de constituir família ao alcançarem a maioridade e, não menos importante, o desejo de ter acesso e o reconhecimento da propriedade individual da terra para dela extrair a própria subsistência.

O processo de transformação do indivíduo como sujeito da ação, na interação com a coletividade, permitia formar o movimento organicamente e, por meio da divisão social das tarefas e dos cursos de formação, avançou-se rapidamente para a formação de novas lideranças, convictas de que era necessário, junto com a conquista da terra, realizar a transformação da sociedade capitalista.

A unidade de ideias e de ações em busca das mudanças estruturais da propriedade da terra e da sociedade, fazia superar as disputas menores e as possíveis desavenças surgidas naquela trajetória, um pouco semelhante ao que disse Walter Benjamin quando extraiu de Lotze a emblemática consideração, a qual 
declara que: "Entre os atributos mais surpreendentes da alma humana... está, ao lado de tanto egoísmo individual, uma ausência geral de inveja de cada presente com relação a seu futuro".(1994, p. 222). Portanto, não se tratava dos Sem Terra não serem sujeitos egoístas, temporariamente organizados coletivamente, mas de indivíduos despidos de inveja competitiva, confiantes na promessa de que, "se permanecessem organizados", todos os envolvidos seriam proprietários de terra.

As dívidas históricas acumuladas pelo Estado contra as populações pobres do campo não se referem às relações de compra e venda, são dívidas criadas e não pagas, pela não efetivação das promessas feitas, primeiro pelo Império, depois pela República. Logo, na década de 1980, os pobres do campo poderiam ter dito: "somos tocados por um sopro de ar que foi respirado antes" (BENJAMIN, 1994, p.223). Ar respirado por quem? Pelos índios massacrados como se fossem inimigos do mundo civilizado; pelos negros escravizados que, ao receberem a notícia da assinatura da lei Áurea, ao mesmo tempo foram informados que a terra agricultável já não os queria como habitantes; e também os descendentes de imigrantes europeus que viram os seus pais e avós constituírem famílias com numerosos filhos, serem impedidos de reproduzirem a mesma trajetória familiar por "falta" de terra.

O ar respirado na década de 1980 já havia sido respirado por diversas gerações que cobravam o atendimento às suas necessidades, mas aquele ar que exalava o cheiro de inúmeras decepções, também aproximava os antepassados dos seus descendentes, que passaram a se denominar como herdeiros, não de coisas, mas de bravura, revolta e resistência. Desse modo, sujeitos maltrapilhos evocavam com gritos de denúncia todas as dívidas anotadas nas paredes daquelas consciências sofredoras e exaltavam os heroicos cobradores dos quilombos destruídos; de Canudos incendiado; do Contestado bombardeado pelos aviões do capital transnacional; das Ligas Camponesas perseguidas e proibidas e, junto, todos os direitos e valores dos líderes, como Zumbi dos Palmares, Antônio Conselheiro, José Maria, João Pedro Teixeira e outros, impedidos de serem universalizados pela truculência do poder dominante.

O mesmo ar da dominação diversas vezes respirado, a partir de 1980 nos mostra na sequência que pouco de transformação e qualidade de vida alcançou-se após três décadas de tanta luta. Em relação a isto, dados de 2010 do Índice de Desenvolvimento Humano Municipal (IDHM) revelam-nos que, apesar do avanço do 
agronegócio, o campo está abaixo da cidade em diversos pontos - de 0,586 contra o outro, que é de 0,750. Uma comparação comprovadora disso se dá quando se observa a renda das famílias urbanas e rurais. Enquanto na cidade ela chega a quase um salário mínimo por família, na agricultura é ainda mais baixa e o valor alcançado é de $R \$ 312,74$ (trezentos e doze reais e setenta e quatro centavos). É disso que nos falam os números da pesquisa do IBGE que apresenta os dados de 2018, mostrando que, em 2017, 54,8 milhões de pessoas viviam abaixo da linha da pobreza.

Em relação ao controle do território e a posse da terra no Brasil, tivemos dois eventos criadores da dívida e o impedimento ao acesso à terra, que foi a divisão do país em capitanias hereditárias seguido da doação de donatarias, como também a aprovação da Lei número 601 de 1850, que ficou conhecida como a "Lei de terras", quando, por ocasião da sua aprovação, a terra juridicamente ficou inacessível a quem não pudesse comprá-la. Assim sendo, “A Lei № 601, de 1850, foi então o batistério do latifúndio no Brasil" (STÉDILE, 2011, p. 23).

O Censo Agropecuário de 2017 revelou com maior precisão no que consiste a concentração da propriedade da terra na atualidade. Dos 5.072.152 de estabelecimentos, 4,1 milhões ocupam $12,8 \%$ da área total produtiva, ao passo que 2,4 mil fazendas detêm 51,8 milhões de hectares.

Essa brutal dívida de negação dos direitos, também encontramos na educação. Os dados da escolaridade no campo são gritantes quando mostram o analfabetismo e o baixo desempenho escolar: 25,8\% da população rural adulta (de 15 anos ou mais) é analfabeta, enquanto na zona urbana essa taxa é de $8,7 \%$. (MEC/PRONACAMPO, 2012)

Quanto à formação de professores, do total de 342.845 professores no campo, 160.317 possuem educação superior; 156.190 possuem apenas o ensino médio e 4.127 ensinam tendo somente cursado o ensino fundamental. No que diz respeito ao Ensino Médio, entre os jovens de 15 a 17 anos, pouco mais de um quinto nessa faixa etária $(22,1 \%)$ estão frequentando esse nível de ensino contra $49,4 \%$ na zona urbana (MEC/PRONACAMPO, 2012).

O segundo aspecto, que se refere a "ocupação de lugar", diz respeito a uma simplificada forma, quando os trabalhadores Sem Terra organizados no MST inseriram-se como sujeitos sociais e políticos sem desagradar as forças já 
existentes, como igrejas, sindicatos, partidos políticos, Organizações não governamentais etc., atuantes ou burocratizadas, formadas antes ou durante a década de 1980. A clareza dos objetivos a serem alcançados pelo MST, partindo dos referenciais de que "a terra esteja nas mãos de quem nela trabalha"; lutar por uma sociedade sem exploradores nem explorados; ser um movimento autônomo dentro do movimento sindical; organizar os trabalhadores na base; estimular a participação dos trabalhadores no sindicato e no partido político; formar lideranças e articular-se com os trabalhadores da cidade e da América Latina; (MST, 1986b), demonstrava que o movimento não surgia para disputar espaço com outras forças aliadas, mas para preencher um lugar para o qual ele fora escalado pelo espaço aberto pela História.

Se a história da luta pela redemocratização do Brasil havia "guardado o lugar" para uma nova construção com aqueles que desejavam profundamente a posse da terra, o MST surgiu para ocupá-lo e o fez segurando nas mãos das Igrejas que atuavam por meio da Pastoral da Terra - CPT, das Comunidades Eclesiais de Base CEBs; dos Sindicatos e oposições sindicais rurais - STR e em estreita sintonia com o Partido dos Trabalhadores - PT e da Central Única dos Trabalhadores - CUT.

A inovação metodológica do fazer da luta social, a humildade da militância e a generosidade dos apoios de entidades e dirigentes sindicais, conscientes da necessidade de um novo tipo de organização, abriram as portas para que essa nova força se estruturasse sob o comando da solidariedade política.

A maneira simples, mas solidamente organizada de se fazer uma ocupação de terra que, no escuro silencioso da noite fazia nascer uma verdadeira ordem de luta e, antes do raiar do primeiro dia, já estava organicamente estruturada; a coordenação, toda ela formada por comissões como segurança, saúde, educação, trabalho, comunicação, formação, e outras; tudo isso cativava, não apenas consciências envolvidas nas responsabilidades, mas também aquelas que à distância esperavam pelo pior.

Praticar um ato de desobediência, afrontar a lei e a "moral" do direito sagrado da propriedade privada da terra, e ir, com representantes, muitas vezes maltrapilhos, até o palácio do governo estadual exigir providências, com uma pauta de reivindicação bem organizada, demonstrava que aquele lugar, antes ocupado somente por autoridades, tinha que abrir espaço para a chegada desse novo sujeito 
coletivo.

$\mathrm{Na}$ mesa de negociação encurtava-se a distância entre governantes e governados e as formas de tratamento, em linguagem coloquial, simplificavam os títulos e os cargos para identificarem-se com tarefas a serem executadas. Ao governador cabia suspender o despejo, não enviando a polícia para realizá-lo; aos secretários de estado, a assistência; ao INCRA, a vistoria da área para desapropriála e aos trabalhadores, a garantia da organização interna do acampamento. E, na saída, aqueles que sempre haviam sido rejeitados e esquecidos eram procurados nas portas das repartições pelos jornalistas para contarem o que haviam acertado.

Naquelas situações realizava-se aquilo que Marx e Engels haviam descoberto em 1845, que "os homens são produtores de suas representações..." (2009, p.94). As representações nos dois sentidos: aquelas de que o esquecido e humilhado, ao respirar o ar de antepassados derrotados, não se intimidava e representava a si e a todos os que o aguardavam para saberem "das notícias". No segundo sentido, as representações das próprias ideias e imaginações de como seria a sensação de ser uma autoridade, liderança e defensor de uma organização, como eram os líderes partidários perseguidos pela classe dominante.

Era o lugar da disputa que propiciava todas essas sensações ao mesmo tempo, engrandecendo por fora aqueles que se faziam notar e deixando a dúvida por dentro, se havia preparo suficiente para enfrentar as plateias, para expor teorias e contestar acusações. O que despertava, então, o interesse pelo estudo, pelo curso de oratória e pelos livros nunca lidos.

O terceiro aspecto refere-se à mística ${ }^{4}$ transformativa - Era a ocupação da terra o lugar social que despertava a mística de fazer-se sujeito da ação e também eticamente bom. Entregar-se por inteiro e estar a serviço da luta era uma decisão instantânea. Aceitar os sacrifícios e transformá-los em aprendizado de

\footnotetext{
${ }^{4}$ Mística significa, o conjunto de convicções profundas, as visões grandiosas e as paixões fortes que mobilizam pessoas e movimentos na vontade de mudanças, inspiram práticas capazes de afrontar quaisquer dificuldades ou sustentam a esperança face aos fracassos históricos. (BOFF, 1999, p.24). Ainda de acordo com Boff a mística político-social está vinculada a uma utopia "capacidade de projetar, a partir das potencialidades do real, novos sonhos, modelos alternativos e projetos diferentes de história [...] desfatalizam a história, não reconhecem como ditado da história a situação injusta imposta e mantida pelas forças opressoras" (p.24). Para Caldart (2001) a Mística é a força, a energia cotidiana que tem animado a família Sem Terra a continuar na luta, ajudando cada pessoa a enxergar e a manter a utopia coletiva. A mística é aquele sentimento materializado em símbolos, que nos faz sentir que não estamos sozinhos e são os laços que nos unem a outros lutadores que nos dão mais força para prosseguir na construção de um projeto coletivo (CALDART, 2001. p.29).
} 
resistência tornava-se um princípio orientador da conduta. Aprender a confiar em pessoas que antes eram todas "estranhas", e juntas formarem a comissão de segurança para zelar pela vida e pelo sono de grandes massas que descansavam no intervalo de alguma batalha, elevava a autoestima pessoal como se uma promoção tivesse acontecido.

A mística de ir buscar pessoalmente a resposta por meio de uma longa marcha, transformando as rodovias em lugares de protestos, passou a ser fortalecida. As marchas longas e desgastantes criavam pelo caminho novas amizades com pessoas solidárias que ofereciam água, acenos, abraços e desejavam sucesso.

No processo formativo individual e coletivo cabia a preocupação com a produção de alimentos na terra conquistada. A necessidade de trabalhar e produzir o próprio alimento na nova terra, mesmo antes de ser desacorrentada da posse do latifundiário, convidava ao plantio. Era o tempo de trabalho, luta social e aprendizado coletivo. De refletir valores. Ser cordiais com a terra e com ascompanhias humanas. Tempo de abandonar as queimadas e não fazer uso de venenos. E a terra respondia assegurando o ciclo de cada cultura de dias, meses e anos. O fazer-se humano também passou pela convivência, por novas formas de trabalho, produção e educação.

\section{Dilemas, contradições e possibilidades}

Ao tratarmos do trabalho e das formas de produção vem-nos logo à mente os primeiros escritos de Marx e Engels, ainda em A ideologia alemã (1845) quando falaram de Feuerbach e a história, e ali esclareceram que os "sábios filósofos" não haviam feito a libertação do homem avançar nenhum passo por terem esclarecido as "fraseologias" da dominação. Sentenciaram que só é possível conquistar a libertação real no mundo real pelo emprego de meios reais e que a escravidão não podia ser superada sem a máquina a vapor, nem a servidão sem a melhora da agricultura. "A "libertação" é um ato histórico e não um ato de pensamento e é ocasionada por condições históricas, pelas condições da indústria, do comércio, da agricultura, do intercâmbio..." (MARX/ENGELS 2009, p. 29).

Para o MST, as necessidades materiais de sua formação exigiram a 
implementação de atos "históricos" (no sentido marxiano) contra o latifúndio, que, na época, ainda não estava tomado pelo agronegócio, embora a sua base tecnológica de agribusiness originada na matriz norte-americana da "revolução verde", já estivesse se disseminando em algumas regiões do país.

Ainda sem a força do agronegócio, dois estorvos associados ao latifúndio ofendiam aos setores conservadores da sociedade: a improdutividade e o uso da violência. Devido à perseguição e a repressão policial em algumas regiões do país, parte das conquistas se deram também em áreas de florestas que serviam de proteção. Mesmo nas regiões mais devastadas, os acampamentos sempre foram estruturados em manchas de reservas de mata ou capoeiras.

As práticas produtivas culturalmente assimiladas, após a terra conquistada, subdividiam-se ancorando-se em dois ramais de um mesmo processo: artesanal e semiconvencional, combinados com a força de trabalho familiar, como também em "grupos coletivos" e, por outro lado, empregavam-se alguns dos componentes da "revolução verde" como, tratores, adubos, sementes híbridas e agrotóxicos. Não havia ainda a preocupação com a preservação das florestas e a consciência do uso de técnicas agroindustriais, embora, espontaneamente, no Norte e Nordeste do Brasil, essas práticas fossem comuns.

No início da década de 1990, quando o agronegócio dava os primeiros sinais de sua pujança, as análises apontavam para a tendência da modernização rápida da agricultura, conforme se pode ver no "Documento básico" do MST que contém as diretrizes básicas para o período de 1989-1993, publicado em março de 1991. Destaca o documento que o processo de modernização, além da concentração das terras, intensificou a mecanização agrícola; ampliou a utilização de adubos químicos e venenos; expandiu o crédito rural para investimentos e custeios para produzir produtos destinados à exportação. Apontou também para o avanço da agroindústria, com o oferecimento de produtos para o mercado interno e a influência sobre os pequenos produtores por meio da produção de sementes, mudas melhoradas e matrizes animais, bem como a expansão dos plantios de florestas homogêneas, como eucaliptos e o uso irracional dos solos, dos recursos naturais, desequilibrando o meio ambiente. Isso tudo representava a inovação tecnológica com o emprego da informática e de outras áreas da ciência.

Se olharmos para a progressão posterior da agricultura, aquilo que estava 
sendo vislumbrado, nem de longe chegaria a ser o que hoje presenciamos. Podemos ter uma ideia da evolução da agricultura capitalista, se observarmos o crescimento da produção de grãos efetivada no Brasil, a partir de 1980. O quadro abaixo nos revela o ano e os milhões de toneladas de grãos produzidas.

Quadro 01- Milhões de toneladas produzidas por ano

\begin{tabular}{|l|l|l|l|l|l|l|}
\hline 1980 & 1990 & 2000 & 2005 & 2010 & 2015 & 2017 \\
\hline 50,8 & 58,2 & 83,0 & 144,7 & 149,2 & 207,7 & 238,0 \\
\hline
\end{tabular}

Fonte: Quadro construído pelos autores com base em dados expostos nos boletins da CONAB.

Pelo quadro acima podemos ver que, entre a década de 1980 e 1990, período em que nasceu e se desenvolveu o MST por todo o país, o volume de produção na agricultura cresceu apenas 7,4 milhões de toneladas. Na década seguinte, conforme revela a análise acima, a modernização tecnológica fez com que de 1990-2000 a produtividade crescesse 24,8 milhões de toneladas de grãos. Foi quando a luta pela terra elevou o seu patamar de disputa e passou a ser uma verdadeira luta pela reforma agrária. Assim passou a ser visto o processo futuro. "Portanto, a realização de uma ampla reforma agrária está vinculada à mudança do atual sistema econômico e terá necessariamente, um caráter socialista” (MST, Documento Básico, 1991, p.20).

O percurso entre o nascimento e o amadurecimento do MST foi muito rápido. Nasceu em 1984 com a determinação de democratizar a posse da terra, tendo como orientação a palavra de ordem formulada para o primeiro congresso realizado em janeiro de 1985, em Curitiba, no Paraná: "Sem terra não há democracia". Revelaria essa intencionalidade que, praticamente nos 5 anos restantes da década, sob um governo de transição, o empenho da militância voltar-se-ia para estruturar o movimento em todas as regiões do Brasil, por meio da luta contra o latifúndio e, obrigatoriamente, inserir-se nas lutas mais amplas como a eleição da Assembleia Nacional Constituinte nas eleições parlamentares de 1986.

As mudanças de estratégias vieram nas primeiras tentativas de implantação do modelo neoliberal, por meio do governo de Fernando Collor de Melo, juntamente com a tendência de modernização da agricultura, apontada pela presença do agronegócio. Estes fatos levaram à realização do Segundo Congresso Nacional, em 
1990, no qual foi afirmada uma nova posição de luta. A palavra de ordem expressava que, para enfrentar aquele momento, era preciso "Ocupar, resistir e produzir".

Naquela ocasião, a discussão sobre o trabalho e a produção nos assentamentos, constantes no "Documento básico do MST", apontou como linhas políticas, dentre outras, que para alcançar o desenvolvimento rural era preciso: "Desenvolver a produção, em maior escala, de produtos agropecuários e agroindustrializados que viabilizem os assentamentos, com mercado e preços compensadores" (MST, 1991, p. 54). Também apontava para a necessidade da mecanização agrícola; a centralização dos negócios de compra e venda e estimulava a formação de agrovilas.

Relacionado ao desenvolvimento do trabalho cooperativo, o documento liberava para a organização de todas as formas de cooperação, sendo "rígido na aplicação dos princípios e flexível em relação às formas" (1991, p. 55). Não aparece ainda, nesse plano "quinquenal" (1989-1993) a preocupação com a agroecologia e a preservação permanente da terra e da natureza.

Vinculada à estratégia de luta e resistência crescia a articulação internacional das organizações camponesas que, já em 1993, davam os primeiros passos para a criação da Via Campesina ${ }^{5}$. Esta sim, por meio de seus encontros, passou a definir uma pauta internacional comum de luta contra os agrotóxicos e pela defesa da agroecologia.

Foi nesse período da segunda metade da década de 1990 que aconteceram os massacres de Corumbiara $(1995)^{6}$ e Carajás (1996) ${ }^{7}$. O Terceiro Congresso,

\footnotetext{
${ }^{5}$ La Vía Campesina é um movimento internacional que articula 150 organizações em 70 países e se considera como um "movimento autônomo, pluralista e multicultural, sem nenhuma filiação política, econômica ou de qualquer outro tipo." O objetivo da Via Campesina é de estabelecer uma articulação, comunicação e uma coordenação de atividades em comum a nível mundial e regional. (VIA CAMPESINA, 2011).

${ }^{6}$ Conflito ocorrido no dia 09/08/1995, às duas horas da madrugada entre 300 policiais do COE (tropa de elite) e trabalhadores acampados na Fazenda Santa Elina, em Corumbiara (RO). Neste conflito, houve aproximadamente 20 trabalhadores desaparecidos, 350 ficaram gravemente feridos, 200 presos e 8 mortos, incluindo uma criança.

${ }^{7} \mathrm{O}$ conflito conhecido como Massacre de Eldorado do Carajás consistiu no assassinato de dezenove trabalhadores rurais sem-terra, mais de 60 trabalhadores feridos e ocorreu em 17 de abril de 1996 na curva do S, no município de Eldorado do Carajás, no sudeste do estado do Pará, decorrente da ação violenta da polícia Militar do citado estado. Os trabalhadores do Movimento dos Sem Terra faziam uma caminhada até a cidade de Belém, quando foram impedidos pela polícia de prosseguir. Mais de 150 policiais - armados de fuzis, com munições reais e sem identificação nas fardas - foram destacados para interromper a caminhada, o que levou a uma ação repressiva extremamente violenta e na morte dos trabalhadores. Vinte anos depois, apenas dois comandantes da operação foram condenados - Coronel Mario Colares Pantoja, condenado a 258 anos, e Major Oliveira, condenado a 158 anos - e estão presos desde 2012. Nenhum policial ou autoridade política foi responsabilizado.
} 
realizado em 1995, apontava para isso e a sensibilidade política havia detectado que a tentativa de isolamento dos movimentos do campo, sob o governo neoliberal de Fernando Henrique Cardoso, era evidente. Por isso, a palavra de ordem orientadora foi: "Reforma agrária, uma luta de todos". O objetivo era envolver todas as forças sociais para o enfrentamento com o neoliberalismo.

Nesse contexto de luta e resistência é que o MST decidiu deslocar o desfecho das suas disputas para as questões do campo para o território urbano e afirmou-se pela realização de grandes marchas em direção às capitais dos Estados e do País, chegando em 17 de abril de 1997 com 100 mil marchantes na capital federal ${ }^{8}$.

No entanto, aquilo que parecia ser um avanço político para o Movimento, esbarrou se no modelo neoliberal implementado com vigor pelo governo de Fernando Henrique Cardoso, limitando os resultados esperados pelo citado movimento. Somando-se a isso, as demais forças de esquerdas como as centrais sindicais, enfraquecidas pela remodelação do mundo do trabalho, cuidavam das suas demandas; o Partido dos Trabalhadores teimava em disputar a presidência da República, flexibilizando os seus princípios e via a radicalização dos movimentos do campo com certo incômodo e pouco se envolvia nos plebiscitos populares convocados contra o pagamento da dívida externa e a implementação da Área de Livre Comércio das Américas (ALCA), contra a privatização da Companhia Vale do Rio Doce, dentre outros.

Com a chegada do Partido dos trabalhadores ao governo, foram adotadas medidas de valorização da grande produção em vistas a exportação de produtos

\footnotetext{
No local onde o massacre ocorreu, hoje está estabelecido o Assentamento 17 de Abril. A maioria dos moradores são sobreviventes da chacina e familiares das vítimas. A data do massacre acabou sendo escolhida pela Via Campesina, organização internacional de camponeses, como o Dia Internacional de Luta pela Terra. Desde então, abril também é marcado como o mês em que são intensificadas as lutas por terras pelo Movimento Sem Terra. É, ainda, uma forma de camponeses e camponesas se unirem para lembrar a data e homenagear as vítimas do massacre. Fonte: http://www.ihu.unisinos.br/78-noticias/588453-17-de-abril-as-marcas-de-um-massacre.

${ }^{8}$ Diante da expressão pública adquirida pelo MST com o sucesso da marcha de 1997, a queda do bloco socialista no Leste da Europa e o esvaziamento da luta pelo socialismo pelas forças de esquerda em todo o continente, o movimento se propôs a convocar o conjunto das forças populares, sindicais e políticas para uma "consulta", mas a intenção era elaborar um "Projeto Popular para o Brasil". O resultado rendeu um consenso rebaixado, principalmente porque cada força assumia o seu modo de ver a conjuntura e, na sua grande maioria seguiram a estratégia petista de disputar as eleições do ano de 2002. A consulta entre as forças de 1997, no entanto, afirmou a criação de uma articulação política denominada de "Consulta Popular" que, por repetir os mesmos rituais das demais organizações reformistas não se afirmou como uma novidade política. Essa suposta divisão de funções enfraqueceu o MST e o fez também relegar as discussões socialistas para um segundo plano. Aos poucos, foi também se acomodando internamente na estratégia petista para as disputas eleitorais vindouras.
} 
agrícolas e com isso desferiu-se o golpe mortal no processo de reforma agrária. $\mathrm{O}$ novo governo, confiante no potencial produtivo do campo brasileiro, intuindo que poderia abrir novos mercados para os produtos agrícolas, ofereceu aos capitalistas as condições básicas para que, em dois ou três anos de governo, a produtividade de grãos dobrasse a quantidade. Do outro lado, o MST, em 2005, tendo até então sido atendido apenas nos aspectos auxiliares por meio das políticas públicas (escolas, convênios para alfabetização de adultos, programas como Pronera) e desatendido no seu eixo estrutural de renovação da força, pela não desapropriação de terras, tentou reverter a política pela pressão por meio da sensibilização social, com uma marcha de quase 20 dias, saindo de Goiânia a Brasília, com 12 mil caminhantes. Mas o efeito foi completamente diferente daquele atingido em 1997(durante o governo $\mathrm{FHC}$ ). Do contrário, ao chegar em Brasília, não havia ninguém esperando e o governo, após intensas negociações, atendeu verbalmente algumas demandas que serviram como estímulo momentâneo e de satisfação aos que haviam caminhado para voltarem para os seus estados, sem que vissem qualquer ofensiva contra o capital, pois as terras agricultáveis do país estavam reservadas para o agronegócio.

Tendo em vista a afirmação de um rumo sustentável, no ano de 2006, a militância foi convocada a fazer um mutirão de discussão em todos os assentamentos e acampamentos com um documento síntese dos debates feitos entre 2001-2006, "A reforma agrária necessária: por um projeto popular para a agricultura brasileira". Nesse debate apareceram os limites e as contribuições de experiências agroecológicas já desenvolvidas e apontou-se para as tarefas a serem desenvolvidas.

Diante de uma conjuntura desfavorável, o MST se volta prioritariamente para as formas de produção, como aparece no documento: "Romper com a monocultura e promover uma agricultura diversificada, sustentável em bases agroecológicas, sem agrotóxicos, gerando alimentos saudáveis..." (2006, p. 26). A isso se soma também as orientações para o "novo modelo tecnológico" que se volta para "desenvolver programas massivos de formação em agroecologia, em todos os níveis, desde o ensino fundamental até a universidade, para atender a juventude do campo..." (2006, p. 28). Esse processo considera que a educação deve estar voltada para a pesquisa participativa, o intercâmbio entre agricultores/as; o programa popular de 
agrobiodiversidade; o programa florestal e para criar um organismo público de certificação, controle e fiscalização de todos os produtos alimentícios agroecológicos.

Por outro lado, o governo não demonstrou sinais de inclinar-se para frear os avanços do agronegócio e a demonstração do modelo econômico adotado para favorecer o grande capital. Foi nos governos de Lula e Dilma que se deu basicamente o oferecimento mais expressivo de créditos subsidiados para o agronegócio. Os valores passaram de 27,6 bilhões de reais no final do governo de FHC, em 2002, para 156,1 bilhões de reais em 2014, conforme destaca o Instituto Lula $^{9}$, no final do primeiro governo de Dilma. Para a agricultura familiar a evolução dos créditos também fora generosa, pois saltou de 2,9 bilhões de reais em 2002 para 24,1 bilhões em 2014.

Para além disso, o agronegócio não fora beneficiado somente com os créditos, mas tinha à sua frente um governo que abria mercados para os seus produtos, nos continentes asiático e africano, como também favorecia as práticas biocidas contra a natureza, encaminhado ao congresso leis, dentre elas a lei 11.105/05, conhecida como "Lei da biossegurança", assinada em 2005 e que liberou a produção de Organismos Geneticamente Modificados ou organismos transgênicos que favoreceu ao setor.

Em 2007, o MST convocou o seu 5o Congresso com a palavra de ordem "Reforma agrária por justiça social e soberania popular". Na verdade, desaparece a decisão do enfrentamento político com o governo, pois acreditava-se que ele "estava em disputa com os setores conservadores".

Apesar das posições "ofensivas" não se constituiu em uma oposição frontal e completa ao agronegócio, pois a matriz produtiva utilizada, em geral ainda era a mesma originada na revolução verde: mecanização, insumos, venenos e, em muitos casos, também usavam-se as sementes geneticamente modificadas nos plantios dos assentamentos. Em outubro de 2013, após as mobilizações de protestos contra o governo, a presidente Dilma, na busca de manter os movimentos do campo a seu lado e não conflitar com os proprietários de terra, lançou o Plano Nacional de Agroecologia e Produção Orgânica, com um valor pífio de créditos, de 8,8 bilhões de reais para três anos, quase nada comparando com os créditos dados para 0

\footnotetext{
${ }^{9}$ www.brasildamudança.com.br/agronegocio/agronegocio/acesso em 23/02/2019
} 
agronegócio.

Em 2014, no final do governo Dilma, com as desapropriações de terra praticamente encerradas, houve a convocação do 6 Congresso nacional. O MST formulou uma palavra de ordem controvertida: "Lutar, construir a reforma agrária popular". No interior do Movimento prosseguem iniciativas razoáveis de produção agroecológica localizadas no Rio Grande dos Sul e no Paraná, mas ainda permanecem sem um projeto político, de modo que essas iniciativas tendem a se inserir no mundo do mercado capitalista.

Nesse contexto, o MST, com a força política reduzida para contestar um projeto ainda em expansão do grande capital na agricultura, passou definitivamente a buscar na alternativa da produção agroecológica, mostrar um contraponto alertando para os perigos do uso abusivo de agrotóxicos e o consumo de alimentos transgênicos. Tem consciência porém, de todo o potencial que o agronegócio ainda guarda consigo e, por isso, defende que o momento exige novas posturas:

Os enfrentamentos com o capital, e seu modelo de agricultura, partem das disputas das terras e do território. Mas se ampliam para as disputas sobre o controle das sementes, da agroindústria, da tecnologia, dos bens da natureza, da biodiversidade, das águas e das florestas.( MST, 2013, p. 32).

É sensível a intenção da busca de alternativas de lutas e enfrentamentos com o agronegócio, mas elas esbarram nas dificuldades reais do acúmulo de forças, por isso as saídas tendem para a organização coletiva do trabalho, bem como da educação voltada para a qualificação técnica.

\section{A educação no MST: em busca de uma pedagogia do trabalho}

O MST se define como uma organização que luta pela democratização da terra e faz disso uma luta também pelo trabalho. De modo que o Movimento tem buscado, ao longo de sua história, relacionar a luta pelo acesso a terra, o trabalho e a educação.

A Educação escolar constitui uma dimensão incorporada à luta pela terra no MST - em todos os acampamentos e assentamentos há escolas. As experiências educativas do MST constituem-se de: Educação escolar em todos os níveis; Educação de Jovens e Adultos; Formação dos Educadores; Encontro dos sem 
terrinha; Cirandas infantis; mobilizações por escolas; Escolas itinerantes; cursos formais.

Como demonstrado nos dados anteriores sobre a educação dos povos do campo, a base social que integra o MST vem de uma população expropriada de basicamente todos os bens materiais e simbólicos, não apenas do direito à terra, mas também à educação, saúde, lazer, descanso, crédito, trabalho e outros. Portanto, a conquista da terra é o primeiro passo em direção à construção de um novo ser humano em todas as dimensões.

Assim, ao lado da luta pela socialização da terra contra a propriedade privada, - MST prioriza também a formação da consciência e esta perpassa o acesso à educação e ao conhecimento, indo ao encontro da argumentação de Lênin (1986), quando ele afirma que a revolução não se constrói com ignorantes, ou melhor, para construir outra sociedade é preciso que os trabalhadores tenham conhecimento para além do senso comum e o domínio do conhecimento científico.

Legitimando esta posição, o MST, no 6ํㅡㄹ Encontro nacional, realizado em Piracicaba (1991), aprovou as linhas políticas gerais da educação e, entre elas, constam também as orientações para a educação nas escolas do MST. As linhas políticas afirmam, entre outras questões, que é preciso desenvolver uma educação com base na realidade, nas experiências acumuladas e preparar crítica e criativamente para a participação nos processos de mudanças da sociedade. De forma coletiva, construir conhecimentos científicos mínimos para o avanço da produção, ampliando e fortalecendo a relação entre escola e assentamento.

Dos princípios elencados, o primeiro é Ter o trabalho e a organização coletiva como valores educativos fundamentais. (MST, documento básico, 1991). Na atualidade, o MST possui uma proposta de educação consolidada, que foi construída historicamente e se encontra sistematizada em vários documentos.

Nesse percurso histórico, o MST tem defendido uma nova concepção de escola pública, gratuita e mantida pelo Estado, mas orientada, de acordo com os interesses dos trabalhadores Sem Terra, conforme defendeu Marx (1992), ainda no século XIX ao falar sobre educação e ensino na Associação Internacional dos Trabalhadores: ela deve ser uma escola pública, gratuita, porém sem o controle ou a intervenção do Estado, a não ser no seu financiamento.

Ao examinarmos os documentos publicados pelo MST no tocante à relação 
entre educação e trabalho, verificamos que, desde o início, há uma preocupação permanente em definir que tipo de educação e de trabalho estavam sendo almejados. Nos escritos iniciais sobre a educação, constata-se a preocupação com a dimensão formativa do trabalho. No Caderno de Formação número 18, publicado em julho de 1991, com o título "O que queremos com as escolas dos assentamentos" é possível constatar a dimensão educativa do trabalho proposta pelo MST.

Os objetivos traçados para as escolas dos assentamentos vinculados ao Movimento são descritos de maneira resumida: Ensinar a ler, escrever e calcular a realidade; Ensinar a fazer fazendo, isto é pela prática; Construir o novo; Preparar igualmente para o trabalho manual e intelectual; Ensinar a realidade local e geral; Gerar sujeitos da história e preocupar-se com a pessoa integral.

Os princípios pedagógicos são enumerados como orientações e conclamando a todos e todas sem terra às atividades educativas misturadas ao trabalho e à organização coletiva: 1) Todos ao trabalho; 2) Todos se organizando; 3)Todos participando; 4) Todo o assentamento na escola e toda a escola no assentamento; 5) Todo o ensino partindo da prática; 6) Todo professor é um militante; e 7) Todos se educando para o novo (MST, 2005, p.37).

Observa-se, ainda, que os princípios traçados pelo MST para as escolas de assentamentos, além de vincular a escola com o trabalho, enfatiza outros aspectos formativos como: a organização coletiva, a participação, a vinculação com a realidade, a prática, além de convocar os educadores à militância, vislumbrando a educação de todos para o novo. Tais preocupações podem ser também constatadas no Boletim da Educação $n^{\circ}$ 01, publicado em 1992; o documento deixa clara a função da escola de assentamento e a preparação para o trabalho quando afirma que

\begin{abstract}
A escola de assentamento deve preparar as crianças para o trabalho no meio rural; a escola deve preparar para a cooperação, ser coletiva e democrática, qualificar as experiências de trabalho produtivo das crianças no assentamento. O ensino deve partir da prática e levar ao conhecimento científico da realidade. (MST, 2005, p. 39).
\end{abstract}

A preocupação do MST com a vinculação da escola ao trabalho aparece conectada à realidade, à coletividade, à cooperação e aos valores humanistas. Para o MST, o grande papel da escola é "ajudar no processo de educação do coletivo, criando condições objetivas para que as crianças se capacitem para a organização 
coletiva, para a cooperação" (MST, 2005, p. 41).

Para orientar as escolas na elaboração dos currículos foi publicado o Caderno de Educação $\mathrm{n}^{\circ}$ 01, com o título: "Como fazer a escola que queremos". Neste caderno o MST deixa clara a sua compreensão de currículo e propõe romper com a forma de currículo apenas centrada em lista de conteúdos. Destaca a importância do planejamento e, neste processo, reafirma a importância da vinculação entre estudo e trabalho, propondo que as crianças aprendam, estudem, se eduquem através do trabalho.

A dimensão educativa do trabalho tem destaque especial no Boletim da Educação $n^{\circ}$. 4, intitulado "Escola, Trabalho e Cooperação", publicado em maio de 1994. Este documento traz uma reflexão sobre o trabalho enquanto princípio educativo, argumentando que o que mais educa as pessoas é a sua ação, a sua prática do dia-a-dia, ou seja, "aprender fazer fazendo"; alerta que não há aí a exclusão da teoria, pelo contrário, a proposta é que exista sim uma teoria, mas que a mesma seja construída a partir de uma prática e visando retornar a ela. É a relação prática-teoria-prática, ou pedagogia da práxis. Outro argumento apresentado no documento é que o trabalho educa porque mexe com as várias dimensões importantes da formação humana, destacando como fundamentais as seguintes dimensões formativas do trabalho: A formação da consciência; produção de novos conhecimentos e habilidades; provocando necessidades humanas superiores (MST, 1994, p.5- 6). No tocante à relação escola e trabalho, o referido Boletim traz algumas indagações ao mesmo tempo que propõe reflexões acerca do trabalho e seu potencial pedagógico, questionando o porquê do trabalho na escola e já apresentando algumas respostas: pela potencialidade pedagógica do trabalho; porque a escola pode ajudar a tornar o trabalho dos alunos mais plenamente educativo, unindo teoria e prática. (MST, 1994)

O MST justifica ainda a relação da escola com o trabalho por duas razões: por ser um elemento formador da consciência e, em segundo lugar, porque ele ajuda a consolidar uma escola na perspectiva do movimento de luta social a serviço da luta da classe trabalhadora. Em síntese, o Movimento Sem Terra, ao propor uma escola do trabalho quer, de acordo com o Boletim no 04:

Chamar atenção e dar ênfase para o sentido social da escola num acampamento ou assentamento; Educar para a cooperação agrícola; Preparar para o trabalho no meio rural; Desenvolver o 
amor pelo trabalho e pelo meio rural; Provocar a necessidade de aprender e de criar; Preparar novas gerações para as mudanças sociais - para lutar pela sociedade sem explorados nem exploradores, e para viver esta nova sociedade. (MST, 2005, p. 9596).

O que se verifica expresso nos documentos acerca da relação trabalho e educação no MST é que a luta social motiva a necessidade da organização coletiva. Os documentos vislumbram desenvolver o trabalho, mas não de forma alienada, mediante a cooperação em diversas frentes, para que os objetivos da luta social sejam alcançados.

Desta forma, observa-se que há uma tentativa de evidenciar o aspecto formativo do trabalho e a necessidade de cooperação e organização coletiva, frutos dos aprendizados da luta e organização política desde as primeiras reuniões nos grupos de famílias, nas comunidades rurais para ocupação da terra e, posteriormente, na organização dos núcleos de base, encontros e cursos. Neste contexto é que o Movimento apreende o trabalho coletivo como indispensável à organização como um todo e em especial as escolas. Para o MST, a realidade objetiva requer "planejar coletivamente a produção; trabalhar, dividindo tarefas e responsabilidades; pensar no avanço do conjunto e não só da família de cada um; lutar juntos por escola, saúde, estrada, superar divergências, etc." (MST, 1992, p. 34). Nesta perspectiva, Vendramini realiza uma crítica à proposta educativa do MST, pois para ela, na educação do MST o trabalho enquanto princípio educativo é visto apenas na sua positividade:

Aparece como elemento educador e formador. É considerado um valor moral, no sentido de que o trabalho educa o ser humano, e todo Sem Terra deve por ele primar, compreendendo-o como dignificante, educativo, enobrecedor. (VENDRAMINI, 2002, p. 137).

Em pesquisas anteriores, Araújo constata (2007, 2010), sobre a educação no MST e seu vínculo com o trabalho, que há atividades laborais planejadas e desenvolvidas nas escolas do MST, no entanto, não se percebe uma discussão sobre a dimensão ontológica do trabalho, sobre a organização do trabalho na sociedade capitalista, ficando tais atividades apenas no âmbito do cumprimento de tarefas para reforçar a organização. Serve de ajuda e colaboração onde acontece a prática, buscando apenas cumprir um princípio pedagógico que está na proposta 
educativa do Movimento, sem estabelecer uma relação direta entre o trabalho manual e o intelectual. Logo, a essência do trabalho esteve presente no modo de organizar as práticas educativas, mas, a nosso ver, faltam reflexões e debates acerca da sua função social e das contradições sobre o que é o trabalho na sociedade capitalista.

Constata-se também que, na maioria das escolas públicas que estão situadas nos assentamentos, a organização do tempo escolar é de apenas quatro horas, sendo que após este tempo cada estudante retorna para a sua casa e, quase sempre, trabalha na propriedade sob a orientação familiar. Desse modo, a organização do trabalho pedagógico se limita a cumprir tarefas nas escolas, muitas vezes de forma mecânica.

$\mathrm{Na}$ atualidade, o fato de o Movimento ter assumido a plataforma da agroecologia, esta vem se implantando nas escolas dos assentamentos, inclusive inserida no currículo escolar em alguns municípios brasileiros. Essas ações podem vir a se constituírem em avanços, dependendo da forma como se dará a vinculação entre a dimensão política e a dimensão agroecológica. Ou seja, as iniciativas são emancipadoras, mas as ações práticas, sem o condutor político ofensivo, não terão o vigor suficiente para fazer e manter a contestação ao agronegócio.

Para a concepção marxista de educação, a união trabalho e ensino não pode se reduzir a uma metodologia didático-pedagógica em sala de aula, ela deve identificar-se com a própria essência do ser humano. Neste sentido, uma educação que se pretenda emancipatória deve estar vinculada às transformações das condições de vida do grupo em que ela está inserida. Para isto, é preciso buscar incessantemente a universalização da educação e do trabalho como atividade humana auto-realizada, oposta à negação dos requisitos mínimos para a satisfação humana e a destruição produtiva. (MÈSZÁROS, 2005).

Ao desenvolver sua proposta educativa numa sociedade contraditória, 0 Movimento esbarra numa série de condicionantes advindas do modo de organização da produção da sociedade onde está inserido. Tonet mostra este dilema quando nos diz que

Certamente, podem-se estabelecer políticas educacionais mais ou menos progressistas e, por isso, a luta nessa esfera não deve ser menosprezada. Porém, o conjunto da educação só poderá adquirir um caráter predominantemente emancipador na medida em que a 
matriz da sociabilidade emancipada - o trabalho associado - fizer pender a balança para o lado da efetiva superação da sociabilidade do capital [...] Propor, hoje, uma "educação emancipadora" não pode passar da simples projeção de um desejo, de um discurso humanista abstrato. O que é possível fazer, hoje, a nosso ver, são atividades educativas que apontem no sentido da emancipação. (TONET, s/d, p. 11).

As tendências progressistas da educação contribuem para que na luta reivindicatória sejam negociados alguns direitos, no entanto, a função das organizações de classe é permanecer na luta de classes e fazer das conquistas reivindicadas mediações para o fortalecimento da luta pela superação do capitalismo.

\section{Considerações finais}

Diante do exposto, é importante ressaltarmos os limites das ideias geradas pelo contexto das contradições históricas, em parte impedidas de serem fortalecidas pela incapacidade de elaboração e implementação de um projeto político coordenado pelo MST e, em geral, pelos movimentos camponeses. Isso se deve também, em grande parte, pela submissão à estratégia das disputas eleitorais assumidas pelo Partido dos Trabalhadores. A expressão dessa referência partidária, moldada conjuntamente, barrou o caminho para qualquer iniciativa diferenciada desde o início da década de 1990 e continua a dificultar a passagem de novas iniciativas até os dias de hoje.

É importante reconhecer que as escolhas políticas nem sempre são facilitadas pelas contradições que se apresentam. O modo de produção capitalista tem por natureza a necessidade de promover superações constantes e avançar por meio das tendências que o constituem. O processo de acumulação de capital na agricultura, em detrimento dos programas de reforma agrária que perturbaram os governos civis, desde 1985 até 2018, se deu por intermédio de diferentes fatores integrados como: a concentração da propriedade da terra, o emprego da tecnologia a serviço do capital, a abertura do mercado externo e a participação ativa da legislação conservadora.

A pequena agricultura, apesar de suas grandes virtudes, para os capitalistas presentes no campo brasileiro ou fora dele, sempre cumpriu um papel marginal, isto porque, embora tendo as condições de produzir todos os tipos de alimentos o Brasil 
sempre importou trigo, milho, algodão, mostrando que o cumprimento da função social da terra nunca foi levado totalmente a sério pelos governos, desde a fundação da república. Para além disso, embora o modo de produção capitalista seja composto por um sistema complexo de relações, a exploração da terra e da natureza sempre esteve embalada pelos interesses mercantis, nesse caso, absorvendo todas as formas de produção.

As formas de produção capitalistas, comandadas nas últimas décadas pelo agronegócio, tornaram-se hegemônicas. Elas determinam os rumos do desenvolvimento das forças produtivas cada vez menos acessíveis e inviáveis para os pequenos agricultores. Evidentemente, as formas de produção capitalista não estão desvinculadas das tendências do próprio capitalismo, apontadas por Marx (1982) como sendo a exploração, a reprodução, a concentração e a expansão do capital; tudo isto acompanhado por uma legislação sanguinária, conforme relatou Marx quando se referiu à expropriação ocorrida na Inglaterra no século XV. Em nossos dias, a natureza "sanguinária" da legislação está em liberalizar as atividades de ataque contra a natureza; o uso indiscriminado de agrotóxicos; a redução dos direitos dos trabalhadores, elevando o teto da idade para a aposentadoria; a redução do valor das pensões.

De outro lado, a agroecologia proposta pelas forças populares do campo, com suas formas de produção diferenciadas, não consegue se vincular às tendências não capitalistas que possam servir como fortalecimento do modo de produção oposto ao capitalismo. É um esforço venerável, mas sem força para impedir o avanço do modelo econômico dominante. Por esta demonstração, os desafios do MST e dos movimentos camponeses deveriam voltar-se para inverter o princípio estabelecido pelo capital, de que "o econômico comanda o processo político", para fazer com que a "política comande a economia". Não esquecendo que política se faz com ideias e ações desintegradoras das forças inimigas, caso contrário, a agroecologia e a educação tendem a desandar para um discurso puramente moralista, que não chegará sequer a imitar a experiência dos primeiros cristãos que resistiram por quase três séculos à perseguição romana, praticando as suas formas de vida religiosa, articuladas com as práticas políticas e conspirativas, voltadas contra 0 império decadente.

Esse comparativo entre épocas pode servir como demonstrativo para os 
movimentos avaliarem a profundidade da aceitação e vinculação das suas práticas ecológicas ao conteúdo da Encíclica “Laudato 'si, mi' signore” (Louvado seja meu senhor) publicada em julho de 2015 pelo Papa Francisco, como se fosse o seu próprio programa político. O documento, tomado como referência programática, expõe criticas e recomendações sobre o meio ambiente, mas não expressa as diretrizes estratégicas para a afirmação da transição socialista. E propor-se a amenizar os impactos destrutivos das ações do capital significa dar conselhos a um perverso que não tem intenção nenhuma em deixar de sê-lo.

$\mathrm{Na}$ atualidade, a agroecologia poderá contribuir para a implementação de formas de produção diferenciadas e influenciar a mudança de comportamentos por meio das práticas de valores morais, mas ela não pode ser o eixo condutor das mudanças estruturais, como não fora o cristianismo nos primeiros quatro séculos. Embora as contestações morais daquela época fossem pertinentes, os cristãos foram agraciados pelas formas de produção e as demais relações feudais que puseram em crise o modo de produção escravista. A presença dos cristãos na desintegração do império, com discurso e ações moralizadoras, contribuíram para que a nobreza legitimasse a ordem feudal por toda a Idade Média. Sem as mudanças estruturais, as pregações ficariam reduzidas às práticas de resistência.

Os desafios extraídos das contradições do capitalismo atual em crise não se materializam atacando as relações marginais e os comportamentos morais. Marx na "Crítica da economia política" afirma que

Uma formação social nunca perece antes que estejam desenvolvidas
todas as forças produtivas para as quais ela é suficientemente
desenvolvida, e novas relações de produção mais adiantadas jamais
tomarão o lugar, antes que suas condições materiais de existência
tenham sido geradas no seio mesmo da velha sociedade (MARX,
1982, p.26).

Desse modo, devemos buscar saber qual é o potencial político que a agroecologia tem para se sobrepor às formas de produção do agronegócio. Seria a própria agroecologia a criadora "das condições materiais geradas no interior da velha sociedade" que efetivaria a transição para a sociedade vindoura?

Tudo isso é importante compreender para evitar que as ilusões ocupem o lugar das formulações conscientes. Insistir em aspectos secundários como se fossem principais contribui apenas para a satisfação reducionista das intenções 
corporativas.

Uma alavanca, por maior que seja, não poderá mover o mais ínfimo corpo se não houver uma base de apoio onde possa ser calçada. Nessa época de esgotamento de processos, o desafio primeiro deve ser o de compreender-se enquanto sujeitos portadores de limites e cada vez mais cerceados na liberdade de gerar condições para a afirmação de uma nova alternativa concebida.

Considerando que parte das limitações rurais e urbanas sejam revertidas nos próximos anos, qual seria o ponto de apoio para calçar a alavanca para o avanço do capital no campo? O processo eleitoral? A mudança em algumas leis?

Está evidente que os desafios não podem ser extraídos das intenções, das vontades e nem dos sentimentos do período passado, mas, fundamentalmente, das contradições que esta época nos apresenta. Por outro lado, os desafios não podem apenas ser extraídos das escolhas já feitas. Se escolho as formas de produção do agronegócio, tenho certos desafios pela frente; se escolho as formas de produção agroecológicas terei outros. Mas o mundo não se divide entre aqueles que defendem a agroecologia e o agronegócio. Por isso esses desafios para o perecimento da sociedade em que vivemos podem ser pouco decisivos.

É certo que, tanto na economia quanto na política, as dificuldades são difíceis de serem superadas quando as opções feitas criaram as próprias armadilhas do enfraquecimento. Nesse caso, a opção feita pelos movimentos do campo, por se colocarem como força eleitoral dos governos passados e a confiança na expressão das leis, como alavancas para moverem o peso inimigo, não encontram mais a base de apoio nem governamental e nem social para qualquer tipo de sustentação. Insistir nisso é optar pelo fracasso.

A agroecologia pode ser vista como forma de trabalho e de produção diferenciada, que no conjunto das disputas estratégicas pode se colocar como alternativa de educação e conscientização, mas, por si só, ela não tem força suficiente para o enfrentamento e a construção de outro projeto histórico. De modo que é importante manter os focos de resistência, mas articulando-os com o projeto político de superação da sociedade do capital.

Em síntese, o fechamento do período da institucionalidade com a "participação popular" esgotou as perspectivas das conquistas negociadas. Há que recolocar as perspectivas para um novo acúmulo de forças, sobre novos 
fundamentos, que não sejam implodidos por uma simples derrota eleitoral.

\section{Referências}

BENJAMIN, Walter. Magia e técnica, arte e política: ensaios sobre literatura e história da cultura. 7 ed. Brasília/DF: Ed. Brasiliense, 1987. Obras escolhidas, vol I.

BOFF, Leonardo, Beto, Frei. Mística e Espiritualidade. Rio de Janeiro: Rocco, 1999.

CALDART, Roseli. O MST e a formação dos sem terra: o movimento social como princípio educativo. Estudos Avançados, vol.15, № 43. São Paulo: 2001.

CONAB, Companhia Nacional de Abastecimento. Acompanhamento de safra brasileira: grãos, quarto levantamento, janeiro 2013/Companhia Nacional de Abastecimento - Brasília: Conab, 2013.

ITERRA, Método Pedagógico. Redação Paulo R. Cerioli. Caderno n. 9, Veranópolis, 2004.

LENIN, V. Que fazer? São Paulo: Hucitec, 1986.

LUXEMBURGO, Rosa. A acumulação do capital: estudo sobre a interpretação econômica do imperialismo. Biblioteca de Ciências Sociais. Trd. Muniz Bandeira. Rio de Janeiro: Zahar, 1970.

MARX, Karl; ENGELS, Friedrich. A ideologia Alemã. São Paulo: Boitempo, 2009.

Processo de Trabalho e processo de valorização. In: ANTUNES,

Ricardo, (org.) A dialética do Trabalho. São Paulo: Expressão Popular, 2004.

Para a crítica da economia política; salário preço e lucro; o

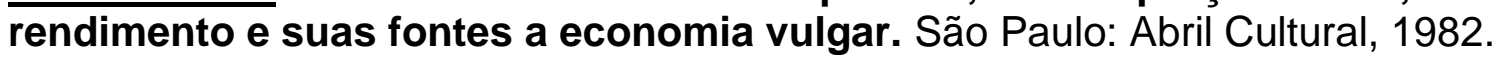

MÉSZÁROS, István. A Educação para Além do Capital. São Paulo: Boitempo, 2005.

MST. Documento básico do MST. São Paulo: MST,1991. MST. Dossiê MST Escola. ITERRA, 2005.

MST - Movimento dos Trabalhadores Rurais Sem Terra. Como fazer a Escola que queremos? Caderno de Educação № 1. São Paulo: MST, 1992.

.Princípios Filosóficos e Pedagógicos. Caderno de Educação n. 8.

Escola trabalho e Cooperação, Caderno de educação n. 04, 2004.

Boletim da Educação. N. 1, 1992. 
.Boletim da Educação. N. 2, 1993.

A reforma agrária necessária: por um projeto popular para a

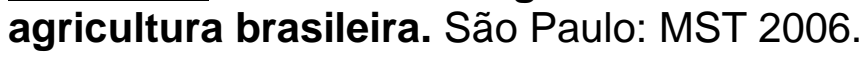

Caminhos da Educação Básica de Nível Médio para a juventude das áreas de Reforma Agrária. Documento final do $1^{\circ}$ Seminário Nacional sobre Educação Básica de Nível Médio na sáreas de Reforma Agrária. Luziânia, GO, 18 a 22 de setembro 2006.

. Construindo o caminho. São Paulo: Secretaria Nacional; 1986b

Programa Agrário. Texto em construção para o VI Congresso Nacional. 3므. ed. setembro 2013.

PISTRAK. Fundamentos da Escola do Trabalho. 4. ed. São Paulo: Expressão Popular, 2005.

SAVIANI, Demerval. Trabalho e Educação: fundamentos ontológicos e históricos. Revista Brasileira de Educação, v. 12, n. 34, jan./abr. 2007.

STEDILE, João Pedro. Introdução. In STEDILE, João Pedro (Org.). A questão agrária no Brasil. Vol 01. Expressão Popular: 2011.

TONET, Ivo. A Educação numa Encruzilhada. Disponível em: http://www.ivotonet.xpg.com.br. Acesso em 20/11/2010.

VENDRAMINI, Célia. A educação, o trabalho e a emancipação humana: uma análise das pesquisas sobre o MST. 32ª Reunião anual da ANPed, 2009, Caxambu, MG.

VIA CAMPESINA. ¿Quién somos?: La voz de las campesinas y de los campesinos del mundo. 9 fev. 2011. p.1-4. Disponível em: https://viacampesina.org Acesso em: 10 mai. 2011. 